\title{
Effect of Agitation, Temperature, and Quenching Medium on Cooling Curve and cooling rate for Steels
}

\author{
Hala S. Hasan \\ Mechanical Eng. Dep. \\ Al-Nahrain University \\ halasalman2006@yahoo.com
}

\author{
Reham H. Khaleefah \\ Mechanical Eng. Dep. \\ Al-Nahrain University \\ rehamhafedh24@yahoo.com
}

\author{
Nasser A. Al haboubi \\ Chemical Eng. Dep. \\ Al-Nahrain University \\ naseer_habobi@yahoo.co.uk
}

\author{
Raad D. Salman \\ Mechanical Eng. Dep. \\ Al-Nahrain University \\ raad.ds12@gmail.com
}

\author{
Received: 4-April-2018 \\ http://doi.org/10.29194/NJES.21040473
}

Revised: 9-May-2018

Accepted: 18-Sep.-2018

\begin{abstract}
The control of quenching process has been investigated in this study by developing a quench system design to simulate the quenching process and measure the time - temperature history inside the sample during the cooling stage. The main purpose of this quench system is to evaluate the quench power of different quenchant at different conditions (type, temperature and agitation).

A stainless steel sample was used with a suitable measurement as a probe in designing this quench system.

The performance of two of quenchants (water and brine) with different conditions was investigated, and the designed probe was used to illustrate the effect of quenching parameters (quenchant type, temperature and its agitation) on cooling curves and cooling rate.The quenching system has proven its ability to work effectively and the results showed that heat transfer properties were significantly affected by quenchant parameters.
\end{abstract}

\section{Introduction}

Quenching, as one of the most important processes of heat treatments which can improve the performance of many metallic alloys greatly, but it can also cause the formation of thermal and transformational stresses which may result in cracks $[1,2]$. Thus, it becomes technical challenge of quenching for every heat treating engineer to choose the quenchant medium and process parameters that will minimize the stresses that can be developed within the part in order to reduce cracking and distortion while at the same time providing heat transfer rates sufficient to achieve the desired a properties such as hardness [3].

Controlling the volumetric fraction of desired phases such as bainite or mostly martensite, morphology of the microstructure, and distortion of the components, is the ultimate goal of the heat treaters in quenching practice. However, the target is rather hard to achieve, due to the complexity of both the process and the mechanisms of heat transfer, and also the mechanics and microstructural evolution associated with the process [4].

Which requires a proper selection of cooling rates fast enough to permit the desired microstructure and in the required depth and prevent the formation of other phases, but slow enough to minimize residual stresses and distortion. The intensity of quenching are affected by changing the quenching parameters (quenchant types, concentration of quenchant, quenchants temperature, and the rate of agitation) [5]. Quenching media generally utilized for steel alloys include brine solution, air, water, oil and polymer solutions in order to get certain hardness and mechanical properties [5-7]. The perfect quenchant is the one that exhibits little or no vapour stage, a fast nucleated boiling stage, and a moderate rate during convective cooling [8]. There are many parameters that influence heat transfer rates during quenching and thus also influencing cooling curve. The main aim of this research is designing a quench system with a stainless steel probe for accurate measurement of temperature profile which can be used to calculate the quench power and the cooling rates for any quenchant. In addition, this project focuses on evaluation experimentally the behavior of different quenchants according to their physical properties (temperature and viscosity) and condition.

R. W. Hines and E. R. Mueller(2009) [9]: compared the performance of $25 \times 100 \mathrm{~mm}$ cylindrical AISI 1546 steel and type 304 stainless steel probes. Their results showed that the Iow-hardenability AISI 1546 probe consistently produced longer A-stage times than the type 304 probe, both of which were quenched in the same quenchant medium This behavior was attributed to phase transformation of austenite to ferrite and pearlite in the AISI 1546 steel. Similar results [10] were obtained for an AlSI 5160 steel probe. Thus, use of a probe constructed of a material that does not exhibit a phase transformation during quenching, such as type 304 stainless steel, allows the results obtained from various 
quenchant media to be compared with out the complication of exothennic transformations. Furthermore, use of such materials eliminates the danger of cracking of the probe; especially in more sever quench media. quenchants. The chemical composition of this steel shown in table 1 .

Table 1: Chemical composition in wt $\%$.

\begin{tabular}{|c|c|c|c|c|c|c|c|}
\hline $\begin{array}{c}\text { Stainless } \\
\text { steel 304 }\end{array}$ & $\mathrm{C}$ & $\mathrm{Cr}$ & $\mathrm{Mg}$ & $\mathrm{Ni}$ & $\mathrm{Si}$ & $\mathrm{P}$ & $\mathrm{S}$ \\
\hline $\mathrm{Wt} \%$ & 0.08 & $\begin{array}{c}17.5 \\
-20\end{array}$ & 2 & $8-11$ & 1 & 0.045 & 0.03 \\
\hline
\end{tabular}

\section{Experimental Methods}

\subsection{Quench system design:}

The evaluation of the quench power of various quenchant needs accurate data for the temperature history within the sample. A controlled quenching system with a stainless steel probe was designed to ensure that the probe is not excessively cooled in air during transferring to quench tank from the furnace.

The system design consists of a data logged system, an axial furnace, 0.5 litre beaker for the quenchant and a K-type thermocouple inserted in to the probe at its geometric center, the probe was held in place by a $35 \mathrm{~cm}$ steel tube. This allowed the temperature data to be taken at probe's geometric center. The tube also guide the movement of the probe as it is dropped, and increases the probe transfer speed from inside the furnace to the quenchant tank using gravity. All components were held in place by a stand to guide the probe as it is traversed from the middle of the furnace to the middle of the quench tank, as shown in figure 1 . The reason of choosing 304 stainless steel because it does not exhibit any phase transformations which make it more accurate to assess the quench power of

The dimension of the probe is 60 long by $1.5 \mathrm{~mm}$ hole in the center $1.5 \mathrm{~mm}$ and length of $3 \mathrm{~cm}$. The length of the probe is 5 times its diameter in order to neglect heat extraction through the ends of the cylinder, as shown in figure 2 .

The surface finish of the probe by machining and grinding the entire probes surface in the same way before quenching, in order to avoid any additional effect for the surface roughness.

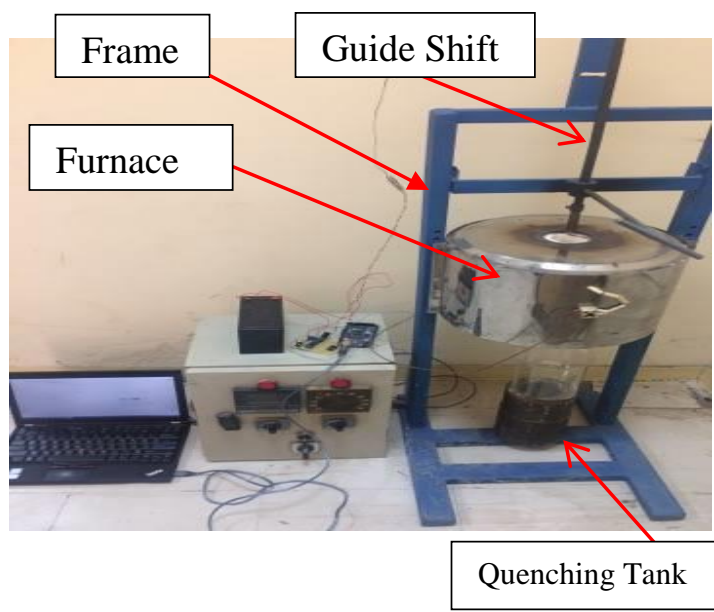

Figure 1: Quenching system

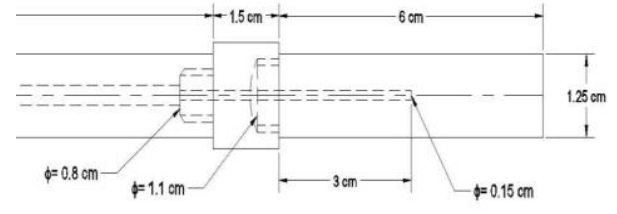

Figure 2: Stainless Steel Probe Design.

\subsection{Probe Preparation:}

The probe was cleaned using an ultrasonic cleaner for $30 \mathrm{~min}$ before quenching in order to avoid surface contamination between the thermocouple and the probe surface and make sure a good contact during measuring temperature, also a small amount of fine graphite powder was used for get better contact between the thermocouple tip and the probe.

The probe with the embedded thermocouple in its center was inserted to the centre of the furnace for $10 \mathrm{~min}$ at least, this period of time is enough to reach the designed quenching temperature.

The thermocouple was connected to the data logging system latterly the probe and the guide shaft assembly was released and falls by gravity until the probe enters the quenching tank.

Different quenchant type and different quenchant temperatures with and without agitation were used to determine the effect of the type, temperature and agitation on cooling curves and heat transfer rate, table 2 shows the testing conditions during the experimental work. 
Table 2: Experimental work condition.

\begin{tabular}{|c|c|c|}
\hline Quenchant type & Water & Brine solution \\
\hline \multirow{3}{*}{ Temperature } & $45^{\circ} \mathrm{C}$ & $45^{\circ} \mathrm{C} 75^{\circ} \mathrm{C}$ \\
& $100^{\circ} \mathrm{C}$ & $100^{\circ} \mathrm{C}$ \\
\hline \multirow{5}{*}{ Agitation } & With and & With and \\
& without & without \\
& agitation & agitation at 3.7 \\
& at $4 \mathrm{~m} / \mathrm{s}$ & $\mathrm{m} / \mathrm{s}$ \\
\hline
\end{tabular}

\section{Results and Discussion}

\subsection{Effect of temperature}

Figures 3 shows the recorded cooling curves of the stainless steel probe along with the corresponding cooling rate $(\mathrm{dT} / \mathrm{dt})$ derived of cooling curve as shown in equation below during quenching with water at $45^{\circ} \mathrm{C}$.

Cooling rate $(\mathrm{dT} / \mathrm{dt})=\frac{T 2-T 1}{t 2-t 1}$

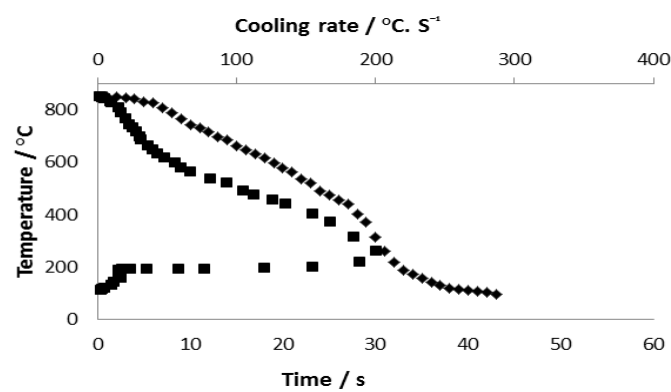

Figure 3: Cooling curve and cooling rate for stainless steel probe quenched in water at 45 ${ }^{\circ} \mathrm{C}$.

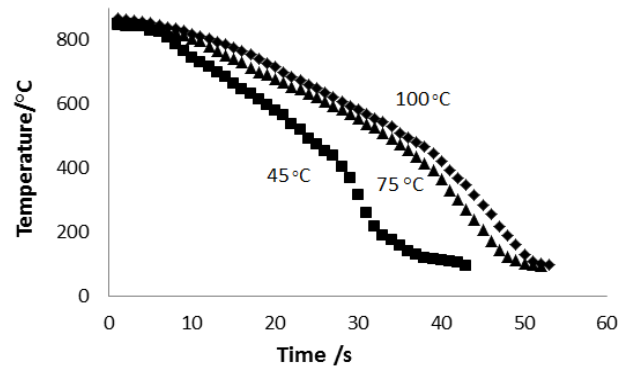

Figure 4: Cooling curves for stainless steel probe quenched in water at different temperature.

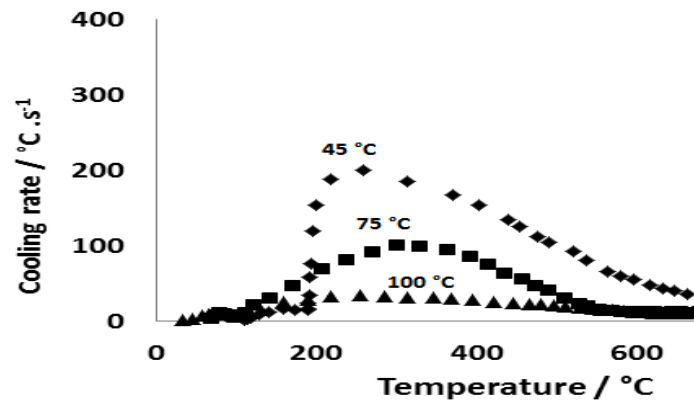

Figure 5: Cooling rates for stainless steel probe quenched in water at different temperatures.
While figures 4 and 5 shows the cooling curves and cooling rates as a function of temperature for quenching the stainless steel probe in water quenchant at different temperatures.

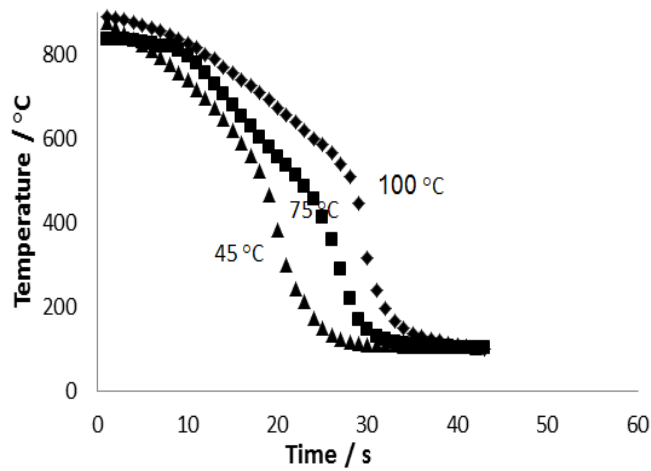

Figure 6: Cooling curves for stainless steel probe quenched in brine solution at different temperatures.

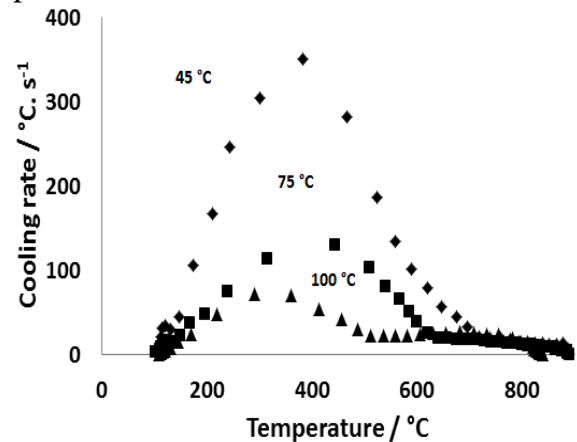

Figure 7: Cooling rates for stainless steel probe quenched at different temperatures of brine solution.

It is clear that The quenching ability of water increases as the water temperature reduced, the maximum cooling rate achieved in water quenching at $45^{\circ} \mathrm{C}\left(200{ }^{\circ} \mathrm{C} / \mathrm{s}\right.$ at $\left.300{ }^{\circ} \mathrm{C}\right)$ at the most important region (where the pearlite transformation usually occurs in the heat treatable steels ) in the range between of 750 $550{ }^{\circ} \mathrm{C}$ the effect of vapour blanket is evident at higher temperature (near the boiling point of the water) an increase in the temperature of the quenching water reduces the energy required to evaporate the water and make the vapour blanket stage longer.

Figures 6 and 7 shows the cooling curves and the cooling rates as a function of temperature during quenching at brine solution, it also shows the same results as water increasing the brine quenchant temperature was actually reducing the cooling rate during the quenching process.

It also shows that brine solution has stronger quenching power than water $350{ }^{\circ} \mathrm{C} / \mathrm{s}$ cooling rate was achieved around $400{ }^{\circ} \mathrm{C}$ comparing with $200{ }^{\circ} \mathrm{C} / \mathrm{s}$ of water at $250 \mathrm{C}^{\circ}$. 


\subsection{Effect of agitation}

Figures from 8 to 11 shows the effect of agitation on cooling curves and cooling rates as a function of temperature for both water and brine solution quenchant at different temperatures, the agitation of water was $4 \mathrm{~m} / \mathrm{s}$ and $3.7 \mathrm{~m} / \mathrm{s}$ for brine solution.

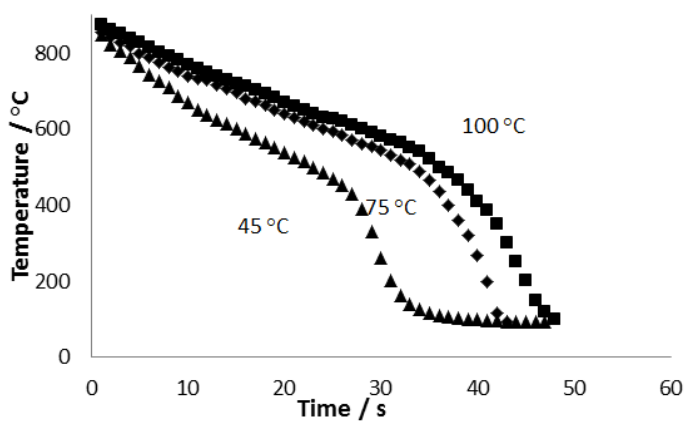

Figure 8: Cooling curves for stainless steel probe quenched in water at different quenching temperature agitated at $4 \mathrm{~m} / \mathrm{s}$.

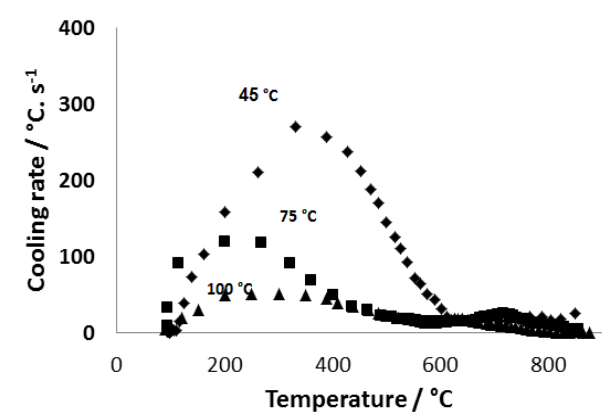

Figure 9: Cooling rates for stainless steel probe quenched in water at different quenching temperature agitated at $4 \mathrm{~m} / \mathrm{s}$.

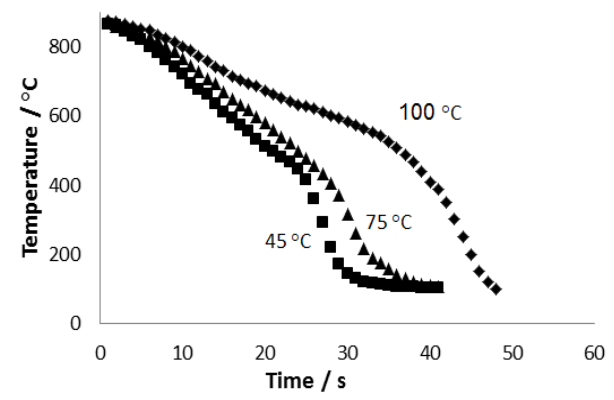

Figure 10: Cooling curves for stainless steel probe quenched at different quenching temperature of brine solution agitated at 3.7 $\mathrm{m} / \mathrm{s}$.

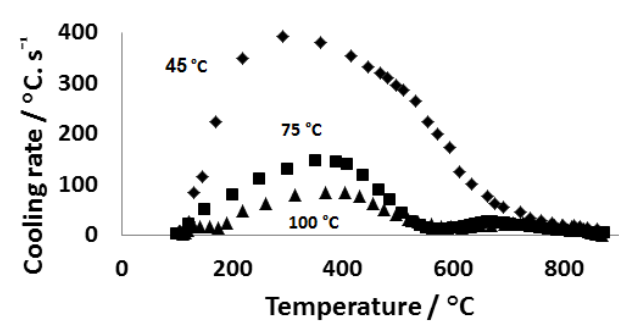

Figure 11: Cooling rates for stainless steel probe quenched in brine solution at different quenching temperature agitated at $3.7 \mathrm{~m} / \mathrm{s}$.

From these figures it's clear that agitation will break the vapor blanket film at the probe surface and speed the transition to the rapid heat transfer stage. What's a more; agitation will also produce smaller, more regular bubbles during the Boiling Stage, which makes quicker rates of heat transfer all through the part. Finally, agitation forces cool liquid to constantly be circulated to the probe in place of the hot liquid at the surface of the part. Therefore, big temperature differences will always exist between the medium and the surface, resulting faster rates of heat dissipation.

\subsection{Effect of quenchant type}

Figures 12 to 15 show a comparison between the cooling rates as a function of temperature for both water and brine solution at 45 and $100{ }^{\circ} \mathrm{C}$ with and without agitation.

The figures show stronger quenching power for the brine solution at all temperatures with and without agitation. The cooling rate is higher that than obtained by water at same temperature, the presence of salt will decrease the formation of vapor blanket and replace it by the boiling stage and at the pearlite transformation region at the heat treatable steels (750-550) ${ }^{\circ} \mathrm{C}$, by adding the salt it's rises the cooling rate to $190 \mathrm{C} / \mathrm{S}$ when it was $95 \mathrm{C} / \mathrm{S}$ in water at same temperature $45^{\circ} \mathrm{C}$.

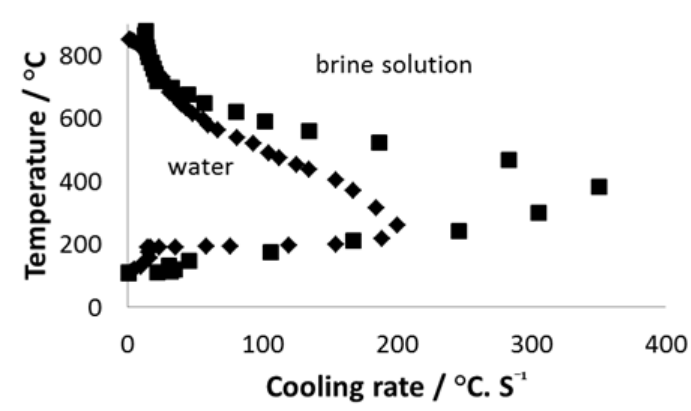

Figure 12: Cooling rate for stainless steel probe quenched in water and brine solution at $45^{\circ} \mathrm{C}$. 


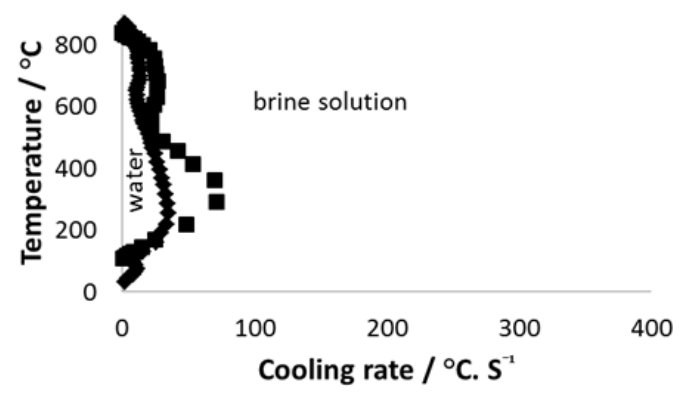

Figure 13: Cooling rate for stainless steel probe quenched in water and brine solution at $100{ }^{\circ} \mathrm{C}$

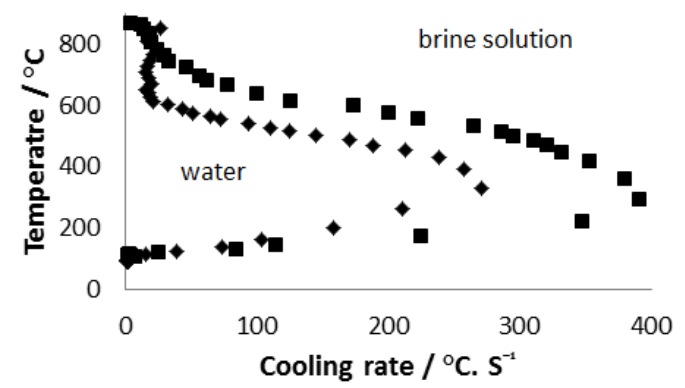

Figure 14: Cooling rate for stainless steel probe quenched in water agitated at $4 \mathrm{~m} / \mathrm{s}$ and brine solution at $3.7 \mathrm{~m} / \mathrm{s}$ at $45^{\circ} \mathrm{C}$.

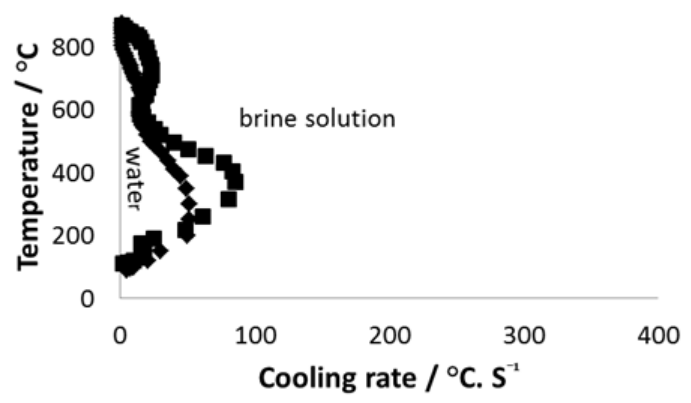

Figure 15: Cooling rate for stainless steel probe quenched in water agitated at $4 \mathrm{~m} / \mathrm{s}$ and brine solution at $3.7 \mathrm{~m} / \mathrm{s}$ at $100{ }^{\circ} \mathrm{C}$.

\section{Conclusion}

The main conclusions from the present study are the following:

1. A quench system with 304 stainless steel probe has been developed to evaluate the quench power of different quenchants.

2. The heat transfer properties are greatly affected by the quenchant parameters (type, temperature and agitation).

3. Agitation will breakdown and stop the vapor blanket stage at the probe surface, agitation will also produce smaller, more regular bubbles during the boiling stage which improve cooling rate at beginning of quenching process $\left(800-500^{\circ} \mathrm{C}\right)$ where the transformations usually happens at the heat treatable steels.

4. Maximum cooling rate was $390{ }^{\circ} \mathrm{C} / \mathrm{s}$ obtained at quenching in brine solution agitated at $4 \mathrm{~m} / \mathrm{s}$.

\section{References}

[1] C. Şimşir and C. Hakan Gür, Journal of materials processing technology, Vol. 207 (2008) pp. 211-221.

[2] D.S. MacKenzie, Z. Li, B. L. Ferguson, "Effect of Quenchant Flow on the Distortion", 5th International Conference on Heat Treatment: Quenching and Control of Distortion, 119-129, 2007.

[3] H. K. D. H. Bhadeshia, in G. Totten, M. Howes and T. Inone, editors, "Handbook of residual stress and deformation of steels" , ASM Intrnational, 2002,pp.3-10.

[4] Shuhui Ma, "A Methodology to Predict the Effects of Quench Rates on Mechanical Properties of Cast Aluminum Alloys" , A Dissertation Submitted to the faculty of the Worcester Polytechnic Institutein partial fulfilment of the requirements for the Degree of Doctor of Philosophy in Materials Science and Engineering, (2006).

[5] H.S.Hasan, M. Peet,J.M. Jalil, and H. K. D. H. Bhadeshia, Heat transfer coefficient during quenching of steel, Heat and Mass Transfer Journal, Vol. 47, 2011, 315-321.

[6] Totten G.E," Steel heat treatment handbook", second ed. Portland: CRC Press Taylor \& Francis Group, 820 ,(2007).

[7] Bernardin J.D and I. Mudawar, "I Validation of the Quench Factor Technique in Predicting Hardness in Heat Treatable Aluminum Alloys", International Journal for Heat Mass Transfer, 1995. 38(5) 863-873.

[8] Herring D.H, Oil Quenching, The HERRING GROUP, Inc. Professional Support Services. http://www.heat-treatdoctor.com/..., (2010).

[9] N.I. Kobasko and D.M. Kostaniuk, "Evaluation of Capacity of Quenchants on Basis using Inner Characteristic of the Boiling Process", Material Science and Heat Treating (MiTOM), No. 10, 2009, p. 21-27.

[10] K. Speith and H. Lange, Journal of Mitt. Kaiser Wilhelm Inst. Eisenforsch., Vol 17, 2010, P 175-184 


\section{تأثثير التحريك، درجة الحرارة ووسط التقسية على منحني التبريد ومعدل التبريد للفولاذ}

قاله سلمان حسن

الخلاصة

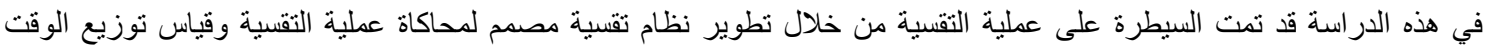

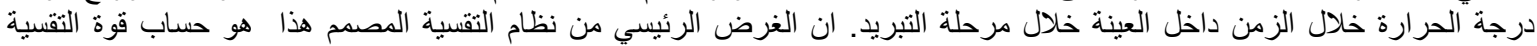

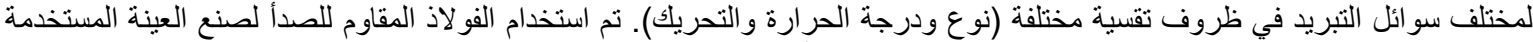

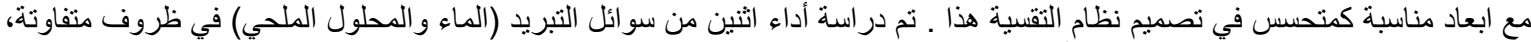

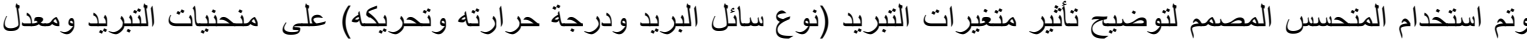

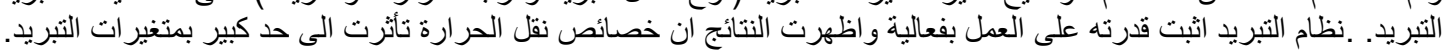

